\title{
BIOQUÍMICA E AÇÃo CITOTÓXICA DE $\alpha$-AMINOCETONAS ENDÓGENAS
}

\section{Fernando Dutra* e Etelvino J. H. Bechara}

Departamento de Bioquímica, Instituto de Química, Universidade de São Paulo, Av. Prof. Lineu Prestes 748, 05508-900 São Paulo - SP

Recebido em 28/6/04; aceito em 21/10/04; publicado na web em 17/2/05

\begin{abstract}
BIOCHEMISTRY AND CYTOTOXICITY OF $\alpha$-AMINOKETONES. $\alpha$-Aminoketones are expected to undergo enolization and subsequent aerobic oxidation yielding oxyradicals and highly toxic a-oxoaldehydes. Our interest has been focused on two endogenous a-aminoketones: 5-aminolevulinic acid (ALA) and aminoacetone (AA), accumulated in porphyrias and diabetes mellitus, respectively, and recently implicated as contributing sources of oxyradicals in these diseases. The final oxidation product of ALA, 4,5-dioxovaleric acid (DOVA), is able to alkylate DNA guanine moieties and expected to promote protein cross-linking. Methylglyoxal (MG), the final oxidation product of AA, is also highly cytotoxic and able to aggregate protein molecules. This review covers chemical and biochemical aspects of these $\alpha$-aminoketones and their putative roles in the oxidative stress associated with porphyric disorders and diabetes.
\end{abstract}

Keywords: 5-aminolevulinic acid; aminoacetone; hexosamines.

\section{INTRODUÇÃO}

$\alpha$-Aminocetonas distinguem-se de outras aminas primárias, entre outras características, pela propriedade de sofrer rápida enolização em pH fisiológico e, em meio aerado, subseqüente oxidação por oxigênio molecular, formando espécies reativas de oxigênio (EROs), tais como oxi-radicais, peróxido de hidrogênio e $\alpha$-oxoaldeídos. A literatura bioquímica e médica das três últimas décadas acentua os papéis cruciais que EROs desempenham no metabolismo celular, como mediadores ou sinalisadores químicos de uma pletora de processos normais e deletérios ${ }^{1}$. Daí a importância de se desvelar o papel pró-oxidante das $\alpha$-aminocetonas nas células.

A química de aminocetonas endógenas começou a interessar nosso grupo de pesquisa há vinte anos, quando foi iniciado o estudo do mecanismo de oxidação aeróbica do ácido 5-aminolevulínico (ALA) catalisada por ferro ${ }^{2}$. O ALA é o primeiro metabólito da via biossintética do grupo heme e está acumulado no sangue e outros tecidos (principalmente fígado e cérebro) de portadores de porfirias hereditárias (ex., porfiria aguda intermitente e tirosinemia) e porfirias adquiridas (ex., saturnismo), sendo reconhecidamente indutor de sérios danos hepáticos e neurológicos a portadores destas doenças. O ácido 4,5-dioxovalérico (DOVA), produto final da oxidação do ALA (Esquema 1), deve ter importante atividade genotóxica, pois é capaz de formar adutos cíclicos em sua reação com resíduos de adenina e guanina de $\mathrm{DNA}^{3}$.

Outra aminocetona estudada nos anos recentes por Bechara e colaboradores é a aminoacetona (AA $)^{4,5}$, um catabólito de treonina e glicina que se acumula em síndromes como o cri-du-chat e a treoninemia ${ }^{7}$, doenças caracterizadas por um alto nível de treonina circulante. Recentemente AA tem sido também apontada, junto com triose fosfatos e acetona, como fonte endógena de metilglioxal (MG) em diabetes mellitus ${ }^{8}$ (Esquema 1). Metilglioxal é um potente agente de modificação de proteínas e DNA e está acumulado principalmente em tecidos susceptíveis a lesões observadas no diabetes: retina, rins e nervos ${ }^{8}$. A descoberta da produção endógena de AA por bactérias e mamíferos ocorreu na mesma época em que

*e-mail: fdutra@iq.usp.br

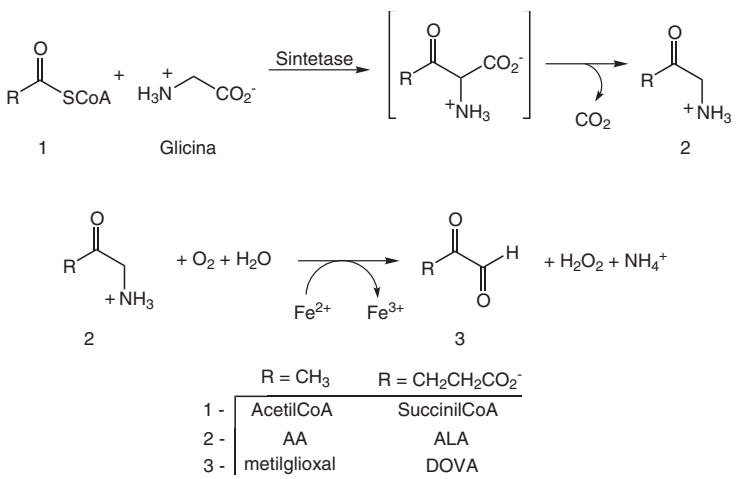

Esquema 1. Reação de biossíntese de aminoacetona (AA) e ácido 5aminolevulínico (ALA) e subsequente oxidação a $\alpha$-oxoaldeídos

despontou crescente interesse por aminocetonas, iniciado com a descoberta do ALA e com a determinação de sua função biológica principal: a biossíntese do grupo heme, formador de clorofila, hemoglobina, citocromos e várias outras hemeproteínas. No final da década de 50, foi demonstrado por Gibson e colaboradores ${ }^{9}$ que partículas isoladas de reticulócitos de galinhas eram capazes de sintetizar ALA, a partir de succinil-CoA e glicina, e AA, a partir de acetil-CoA e glicina. A reação de síntese de ALA e AA é, portanto, essencialmente a mesma (Esquema 1).

As $\alpha$-hexosaminas também pertencem à classe das $\alpha$ aminocetonas endógenas e são os análogos estruturais das hexoses, em que o grupo 2-hidroxila foi substituído por um grupo amino. Sua oxidação aeróbica também produz $\alpha$-oxoaldeídos ${ }^{10}$. Recentemente, as $\alpha$-hexosaminas têm sido relacionadas com o controle metabólico da secreção da leptina, proteína sinalizadora de saciedade, e com um possível papel de "sensores" nutricionais ${ }^{11,12}$.

Na primeira metade do século passado ${ }^{13}$, Szent-Györgyi já havia ressaltado as propriedades estruturais e reacionais de compostos $\alpha$-dicarbonílicos, que os tornariam metabólitos protagonistas de processos deletérios a organismos vivos, particularmente o envelhecimento $^{8,13}$. A formação de bases de Schiff entre cada um dos grupos carbonila do composto $\alpha$-dicarbonílico e do grupo amino 
de proteínas levaria à agregação e desnaturação delas através de ligações cruzadas (Prot-N=CR-CR=N-Prot). Outra importante consequência biológica da reação de Schiff entre metabólitos $\alpha$ dicarbonílicos e proteínas são os adutos fluorescentes denominados Produtos Finais de Glicação Avançada (AGE, de "Advanced Glycation End-products") ou produtos de Maillard, tais como a pentosidina $^{14}$. A pentosidina é um tipo de AGE, formado através de ligações cruzadas entre resíduos de lisina, arginina e o $\alpha$-dioxoaldeído de pentoses (Figura 1). Os AGEs são conhecidos por sua capacidade de se ligarem a receptores celulares específicos, podendo dar início a uma série de eventos distintos, entre eles a indução de citocinas e fatores de crescimento ${ }^{15,16}$, o estabelecimento de estresse oxidativo ${ }^{17}$ e a regulação da adesão celular ${ }^{18,19}$.

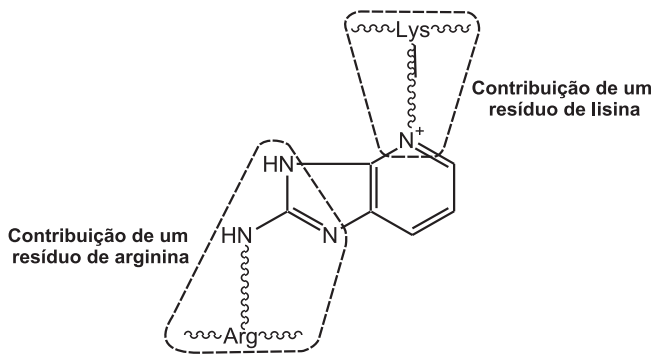

Figura 1. Estrutura da pentosidina. Produto final de glicação avançada (AGE) entre a pentose e resíduos de lisina e arginina de proteínas

Nesta revisão, discutiremos os seguintes aspectos da bioquímica e ação citotóxica de $\alpha$-aminocetonas: metabolismo do ácido 5-aminolevulínico, aminoacetona e hexosaminas; conexões entre estes metabólitos e as porfirias, diabetes, $c r i-d u$-chat e estresse oxidativo e mecanismos de oxidação não-enzimática destes metabólitos, com geração de espécies reativas de oxigênio.

\section{METABOLISMO DO ÁCIDO 5-AMINOLEVULÍNICO (ALA)}

As porfirias, hereditárias ou adquiridas, são um grupo de desordens associadas à insuficiência ou inibição enzimática da via biossintética do grupo heme (Esquema 2), levando ao acúmulo de ALA (formado na primeira etapa da rota) nos tecidos e à excreção urinária deste excesso. Tradicionalmente, as porfirias têm sido agrupadas em tipos eritropoiéticos e hepáticos, dependendo se a produção excessiva dos intermediários se realiza primariamente na medula óssea ou no fígado, respectivamente, sendo que as porfirias com sintomas neuroviscerais são comumente chamadas de "porfirias agudas".

No grupo das porfirias hereditárias, incluem-se a porfiria aguda intermitente (PAI), atribuída à biossíntese deficiente da porfobilinogênio (PBG) desaminase $\mathrm{e}^{20}$, e a tirosinemia hereditária, resultante de forte inibição competitiva da ALA desidratase por succinilacetona $\left(\mathrm{k}_{\mathrm{i}}=0,03 \mu \mathrm{M}\right)$. Em ambos os casos o resultado é o aumento da concentração tecidual de ALA. A succinilacetona, por sua vez, é acumulada como consequiência de biossíntese deficiente da fumarilacetoacetato hidrolase durante o catabolismo de tirosina ${ }^{21}$. No grupo das porfirias adquiridas, destaca-se a intoxicação por chumbo (saturnismo), com efeitos bioquímicos e biológicos multifatoriais, atribuído primariamente à inibição da ALA desidratase por $\mathrm{Pb}^{2+22}$. Sabe-se há muito tempo que o acúmulo de ALA e PBG em fluidos celulares e em tecidos está diretamente relacionado com o quadro clínico da $\mathrm{PAI}^{23,24}$. Muitos danos ao sistema nervoso periférico e central têm sido observados, incluindo desmielinização e vacuolização de neurônios ${ }^{25-28}$. A alta incidência de câncer prímário

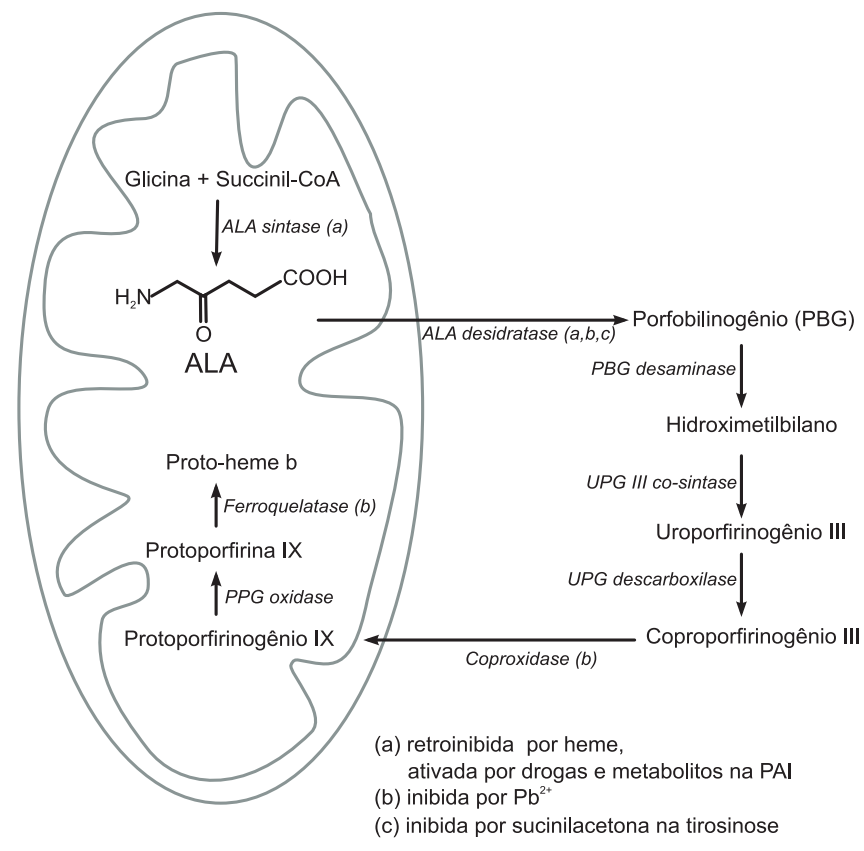

Esquema 2. Rota biossintética do grupo heme

de fígado em PAI e tirosinemia hereditária tem sido associada com a frequência de ataques agudos nos pacientes, quando os níveis de ALA plasmático atingem aproximadamente 100 vezes o valor normal $(\sim 0,26 \mu \mathrm{M})^{3,29-31}$. Esta observação tem sido associada ao potencial carcinogênico do ALA.

Bechara e colaboradores demonstraram in vitro que ALA sofre enolização e subseqüente autoxidação mediada por superóxido com produção de $\mathrm{H}_{2} \mathrm{O}_{2}$ e, conseqüentemente, geração de radicais $\mathrm{HO}^{*}$ via reação de Fenton ou reação de Haber-Weiss na presença de íons de ferro $^{32}$. Reações de autoxidação de compostos $\alpha$-hidroxicarbonílicos (ex., diidroxiacetona ${ }^{33}$ e glicose ${ }^{34}$ ), analogamente à autoxidação de polifenóis (ex., ácido homogentísico ${ }^{35}$ ) e aminofenóis (ex., divicina ${ }^{36}$ ), também possuem como etapa limitante da velocidade a enolização do substrato, ou seja, são os enóis correspondentes que, de fato, sofrem a oxidação. Ao longo da última década, Bechara e colaboradores mostraram tanto in vitro como in vivo que o ALA é de fato capaz de gerar EROs e DOVA, os quais são capazes de oxidar várias biomoléculas e estruturas biológicas supramoleculares, tais como sinaptosomas e mitocôndrias. Os resultados descritos alicerçam a seguinte proposta mecanística para explicar o potencial biológico pró-oxidante de ALA (Esquema 3):

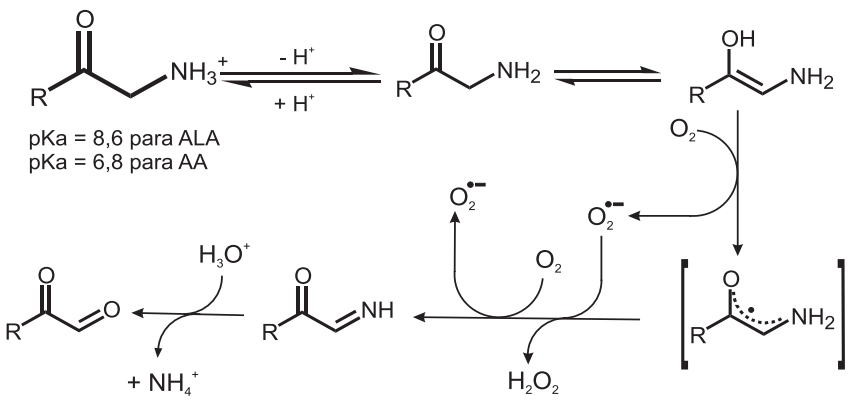

$\mathrm{R}=\mathrm{CH}_{3}$, para aminoacetona/metilglioxal

$\mathrm{R}=\left(\mathrm{CH}_{2}\right)_{2} \mathrm{COOH}$, para ácido 5-aminolevulínico/ácido 4,5-dioxovalérico

Esquema 3. Mecanismo de oxidação aeróbica não enzimática de $\alpha$ aminocetonas 
Após enolização, ALA sofre reação de oxidação por oxigênio com formação do radical enoil ALA', enquanto oxigênio é reduzido a ânion radical superóxido, $\mathrm{O}_{2}{ }^{--}$. Tanto $\mathrm{O}_{2}{ }^{-}$quanto $\mathrm{ALA}^{\bullet}$ podem propagar a cadeia de reação. A oxidação de ALA` produz a imina de ALA ( $\mathrm{ALA}_{\text {imino }}$ ) que, após hidrólise, produz DOVA e $\mathrm{NH}_{4}^{+} \mathrm{em}$ quantidades estequiométricas em relação ao $\mathrm{O}_{2}$ consumido, enquanto $\mathrm{O}_{2}{ }^{--}$pode sofrer dismutação ou redução a $\mathrm{H}_{2} \mathrm{O}_{2}^{2}$.

O ácido 4,5-dioxavalérico (DOVA) é o produto final de oxidação do ALA e também está acumulado em porfirias. O DOVA pode promover alquilação de bases de DNA assim como outros derivados carbonílicos, tais como malondialdeído, acetaldeído e metilglioxal. Assim, Douki e colaboradores ${ }^{3,37}$, trabalhando tanto com nucleosídeos quanto com DNA isolado, provaram que DOVA atua como um eficiente agente alquilante de resíduos de guanina do DNA. Foi sugerido que a primeira etapa da alquilação do DNA envolve a formação de uma base de Schiff entre o amino grupo $N_{2}$ da 2'-deoxoguanosina (dGuO) e a carbonila do DOVA.

Demonstrou-se que a oxidação de ALA é particularmente importante em cérebro, músculos e fígado de portadores de porfirias. As EROs produzidas durante oxidação aeróbica de ALA mostraram-se efetivas para (Figura 2) 2,38-50:

1. in vitro, lesar tanto proteínas quanto liposomos, mitocôndrias, sinaptosomas e DNA, além de provocar liberação de ferro de ferritina e ativar a proteína reguladora de ferro IRP-1;

2. em ratos injetados com ALA ou com o éster metílico da succinilacetona (SAME, um forte inibidor da ALA desidratase), mobilizar ferro para o fígado e para o cérebro, degradar mitocôndrias de fígado e dos músculos sóleus e gastrocnemius, peroxidar membranas de vários tecidos, lesar receptores gabaérgicos e induzir a biossíntese de enzimas anti-oxidantes (superóxido dismutase e glutationa peroxidase) e

3. em pacientes de PAI, tratados ou não com hemina, e trabalhadores da indústria intoxicados por chumbo, induzir peroxidação lipídica e indução da biossíntese daquelas enzimas antioxidantes como resposta adaptativa de proteção.

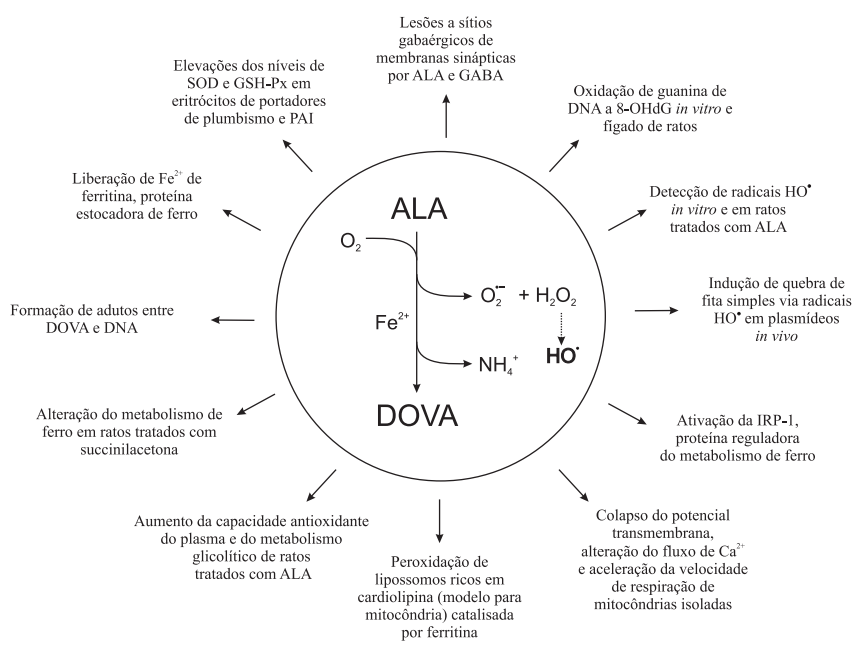

Figura 2. Danos oxidativos a biomoléculas e células promovidos por ALA

Neste contexto, é aparentemente paradoxal o uso recente de ALA em terapia fotodinâmica (PDT, de "photodynamic therapy") como gerador endógeno de porfirinas (fotossensibilizadores). A PDT é atualmente um tratamento de escolha contra o câncer, único ou coadjuvante da abordagem quimioterápica, cirúrgica ou radiológica. Baseia-se na interação entre luz, oxigênio molecular e um fotossensibilizador - ação fotodinâmica - com a formação de oxigênio singlete e radicais livres citotóxicos capazes de destruir cé- lulas tumorais ${ }^{51}$. A PDT baseada na administração do ALA mostrase promissora principalmente no tratamento de desordens dermatológicas, tais como câncer de pele não-melanômico, psoríase e acne ${ }^{52,53}$. Porém, apesar da eficácia do ALA e seus ésteres na PDT e de seu uso estar cada vez mais difundido, há efeitos secundários e indesejáveis desta terapia sobre células sadias ${ }^{54}$. Estes efeitos incluem disfunções hepáticas, que têm sido explicadas por vários grupos de pesquisa ${ }^{55,56}$ através do mecanismo de oxidação aeróbica de ALA proposto por Bechara e colaboradores ${ }^{2}$.

Mais detalhes sobre aspectos químicos, bioquímicos e médi$\cos$ das porfirias são oferecidos pela revisão completa publicada por Onuki e colaboradores ${ }^{57}$.

\section{METABOLISMO DA AMINOACETONA (AA)}

Elliott ${ }^{58}$ foi o primeiro a demonstrar que suspensões de células de Staphylococcus aureus eram capazes de metabolizar treonina com a conseqüente produção de AA, caracterizada por métodos de cromatografia em papel. Esta bactéria também foi capaz de metabolizar glicina com a formação de AA, o que levou Elliott ${ }^{58,59}$ a propor dois mecanismos distintos de formação de AA por Staphylococcus aureus. Nestes trabalhos, foram identificadas três enzimas que catalisam a degradação de treonina: (i) treonina desidratase, formadora de 2-oxobutirato $\mathrm{NH}_{4}^{+}$; (ii) treonina aldolase, produtora de acetaldeído e glicina e (iii) treonina desidrogenase, fonte de 2-amino-3-oxobutirato ${ }^{60-62}$ sendo apenas a última de origem mitocondrial. Bird e Nunn ${ }^{61}$ estimaram que as atividades destas três enzimas-chave, no fígado de ratos alimentados, normalmente mobilizam 10, 3 e $87 \%$, respectivamente, da treonina hepática.

Boylan e Dekker ${ }^{63}$, em 1981, foram os primeiros a purificar a treonina desidrogenase, dando novo impulso aos estudos desta rota metabólica. Tressel e colaboradores ${ }^{64}$ demonstraram que a treonina desidrogenase está associada fisicamente a outra enzima, a aminoacetona sintetase, formando o que eles denominaram de Complexo de Clivagem da Treonina (CCT). A proposta mecanística destes pesquisadores implica na ação direta do CCT sobre treonina, catalisando a conversão desta em glicina (Esquema 4).

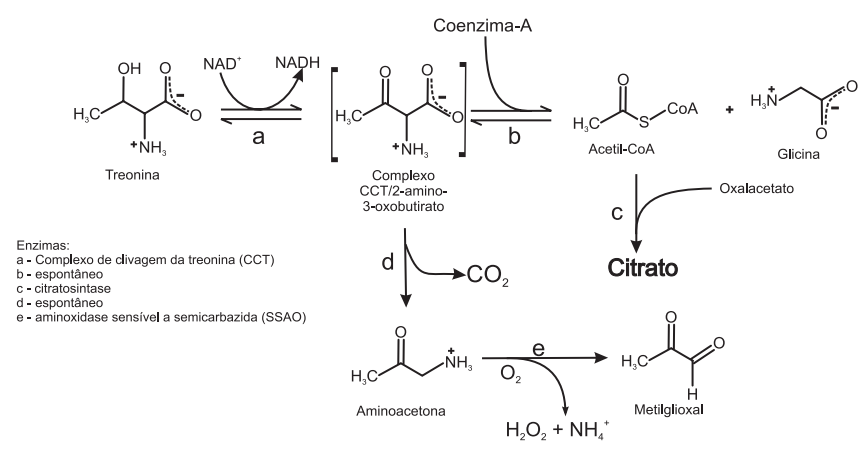

Esquema 4. Metabolismo da treonina

A conversão de treonina a glicina por CCT é dependente de coenzima-A (CoA), ou seja, a abundância de CoA favorece a conversão de treonina a glicina e sua ausência favorece a formação de AA. Desde que ambos $\mathrm{NAD}^{+}$e CoA são cofatores do catabolismo da treonina e da glicina, o controle desta via metabólica depende das relações mitocondriais $\mathrm{NAD}^{+} / \mathrm{NADH}$ e CoA/acetil-CoA ${ }^{65}$. Normalmente o catabolismo da treonina produz glicina e acetil-CoA, contudo acredita-se que em situações de ceto-acidoses, como aquela de diabéticos, onde os níveis de acetil-CoA estão aumentados, a treonina é catabolisada a AA, levando ao seu acúmulo em tecidos destes indivíduos ${ }^{66}$. 
Por outro lado, o desaparecimento de AA em fígado de ratos mostrou-se dependente de oxigênio, fato este confirmado pelo decréscimo de $90 \%$ na velocidade de reação quando se borbulhava $\mathrm{N}_{2}$ no meio reacional ${ }^{62}$. Ray e Ray ${ }^{67,68}$ descreveram a formação de $\mathrm{MG}$, a partir de AA, catalisada por uma aminoxidase presente no plasma e no fígado de ruminantes. Esta aminoxidase foi purificada e estudada com diversos substratos, porém AA se mostrou o mais reativo de todos $\left(\mathrm{K}_{\mathrm{m}}=9 \mu \mathrm{M}\right.$, para a enzima hepática de caprinos), o que levou estes pesquisadores a acreditarem que esta enzima tinha especificidade para formação de MG (Esquema 4). Posteriormente, constatou-se que a enzima descrita por Ray e Ray pode ser classificada como uma monoamina oxidase sensível à ação de semicarbazidas (SSAO, "semicarbazide sensitive amine oxidase") e seus substratos são aminas primárias, sendo as mais reativas a AA, a metilamina $^{69}$ e a benzilamina (não endógena) ${ }^{70}$.

A SSAO é uma glicoproteína dependente de cobre e deve ter como cofator um grupo do tipo 6-hidroxidopa ou um piridoxal ou, ainda, um grupo pirroloquinolina quinona. Todos estes fatores possuem um grupo carbonila sensível à inibição por semicarbazidas e hidrazinas $^{71}$. Daí o fato de aminoguanidina, uma hidrazina nucleofílica, ter se mostrado eficiente inibidora da formação de AGEs, levando à diminuição de formação de placas arteroscleróticas e prevenção da nefropatia em diabetes induzido em ratos ${ }^{71}$. Como está distribuída na vasculatura e no plasma, acredita-se que sua função não seja apenas a de produzir MG a partir de AA, mas também de metabolizar aminas circulantes, endógenas ou não, que possam ter atividades farmacológicas ou deletérias ${ }^{72}$.

\section{METILGLIOXAL E DIABETES MELLITUS}

A descoberta de que o diabetes mellitus é um estado metabólico caracterizado, entre outros fatores, pelo aumento na concentração de AA e de que a SSAO circulante é elevada, tanto no diabetes mellitus do tipo I (insulino-dependente, IDDM) quanto no diabetes mellitus do tipo II (insulino-independente, NIDDM) ${ }^{73}$, levou vários pesquisadores a investigar os mecanismos de ação desta enzima e avaliar sua atividade nos tecidos e plasma dos pacientes. A atividade normal da SSAO em plasma humano é de aproximadamente $350 \mathrm{mU} / \mathrm{L}$, sendo que os valores aumentam consideravelmente em pacientes diabéticos: $641 \mathrm{mU} / \mathrm{L}$ para diabetes tipo I e $619 \mathrm{mU} / \mathrm{L}$ para diabetes tipo $\mathrm{II}^{73}$. Pacientes com falha cardíaca congestiva também possuem níveis elevados de atividade de SSAO (590 mU/L), porém não há informações sobre a causa desta elevação ${ }^{74}$.

Apesar de estar distribuída em diversos tecidos humanos, são os vasos sanguíneos que possuem maior atividade da $\mathrm{SSAO}^{71}$. Localiza-se também em retina e microvasos cerebrais ${ }^{75}$, cartilagens $^{76}$, útero, uretra, vasos deferentes ${ }^{77}$, rins ${ }^{78}$ e na circulação sanguínea ${ }^{79}$. A SSAO em mamíferos está ligada predominantemente na membrana plasmática de tecidos, especialmente em células de músculo liso ${ }^{80}$. Foi provado que culturas de células de músculo liso vascular secretam uma forma solúvel de SSAO, indicando a possível origem da SSAO circulante $^{81}$. Apesar de sua função metabólica ainda não ter sido esclarecida inequivocamente ${ }^{70}$, acredita-se que tenha papel inibitório da angiogênese em diabéticos, daí seu possível envolvimento na nefropatia, neuropatia e retinopatia típicas desta doença ${ }^{82}$.

A ação de SSAO sobre AA, com a conseqüente formação de MG, peróxido de hidrogênio e oxirradicais, espécies reconhecidas como citotóxicas (Esquema 5), tem sido proposta como potencial fonte de espécies reativas de oxigênio (EROs) e consequente causadora das disfunções vasculares observadas em pacientes diabéti$\cos ^{75,82,83}$.

Nos últimos anos, o MG tem sido associado ao desequilíbrio redox encontrado por diversos grupos ${ }^{82,84,85}$ em diabetes mellitus,

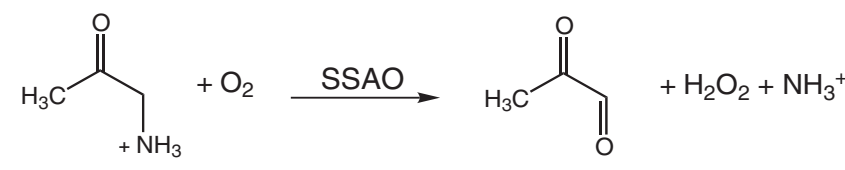

aminoacetona metilglioxal

$\mathrm{H}_{2} \mathrm{O}_{2}+\mathrm{Fe}^{2+} \longrightarrow \cdot \mathrm{OH}+\mathrm{HO}^{-}+\mathrm{Fe}^{3+} \quad$ (Reação de Fenton)

Esquema 5. Oxidação de AA catalisada por SSAO

mas os mecanismos que levam a esta alteração ainda não estão completamente estabelecidos. Neuropatia, nefropatia e retinopatia são alguns dos distúrbios que estão relacionados com a acelerada arteriosclerose causada pelo diabetes em decorrência da ação do MG sobre proteínas, provocando a formação de $\mathrm{AGEs}^{82}$. A concentração normal estimada de $\mathrm{MG}$ em plasma está na faixa de $5 \mu \mathrm{M}$, mas atinge valores 5 a 6 vezes mais altos em pacientes de diabetes tipo I e 2 a 3 vezes em pacientes de diabetes tipo II $^{86}$.

São conhecidas três rotas metabólicas de formação de MG em mamíferos ${ }^{87}$. Uma delas sugere a formação de MG a partir de trioses fosfato e outra, a partir de corpos cetônicos. Segundo Kalapos ${ }^{88}$ estas duas rotas são responsáveis por $90 \%$ da quantidade de MG formada no organismo. Uma terceira rota leva à formação de $\mathrm{MG}$ a partir de glicina e treonina com a formação prévia de AA, como discutido anteriormente. Apesar de esta terceira rota aparentemente ser menos importante na formação do MG em organismos normais $(\sim 10 \%)$, o fato de a concentração de SSAO estar aumentada em tecidos suscetíveis a danos causados no diabetes ${ }^{82,84}$ é um indício do papel da SSAO como fonte de pró-oxidantes $\left(\mathrm{H}_{2} \mathrm{O}_{2}\right.$ e radical hidroxil) e agregador de proteínas (MG).

Aceita-se hoje que a principal rota de desintoxicação do MG inclui o sistema enzimático das glioxalases. Este sistema, descrito em 1913 por Dakin e Dudley ${ }^{89}$ e por Neuberg ${ }^{90}$ de forma independente, contém duas enzimas - a glioxalase I e a glioxalase II - e mostrou-se capaz de transformar $\alpha$-oxoaldeídos em ácido pirúvico ou ácido $\alpha$-cetoglutárico, a partir, respectivamente, de MG e DOVA. Ambos são metabólitos envolvidos na produção de ATP, através do ciclo do ácido cítrico.

Muitas dúvidas ainda pairam sobre a função biológica do sistema das glioxalases, mas sabe-se que elas estão presentes no citossol de células e organelas celulares (principalmente mitocôndrias) e parecem cruciais para o suporte da vida ${ }^{91}$. Foi determinado que a glioxalase II é a enzima limitante da velocidade da reação, mas nos dois tipos de diabetes a atividade da glioxalase I está significativamente elevada e a atividade da glioxalase II, muito reduzida ${ }^{92}$. Como o MG acha-se em concentrações elevadas em diabéticos, pode-se concluir que há também um acúmulo de $S$-D-lactoilglutationa (Esquema 6). O acúmulo de MG e $S$-D-lactoilglutationa é um forte indício de um possível papel de MG como depletor de glutationa reduzida (GSH), importante na desintoxicação de $\mathrm{H}_{2} \mathrm{O}_{2}$ e hidroperóxidos lipídicos. Como resultado final, seriam exacerbadas a produção e a atividade deletéria de EROs no diabetes ${ }^{93}$. Importantes relatos na literatura, tais como a concentração de MG em cristalino humano ser 20 vezes maior que sua concentração plasmática $^{94}$ e bastante elevada em rins e sangue de pacientes diabéticos $^{78,95}$, reforçam um possível papel do MG nas manifestações clínicas típicas do diabetes.

Além de exibir as propriedades pró-oxidantes mencionadas acima, o MG mostrou-se um potencial agente mutagênico endógeno, tal como previsto por Szent-Györgyi ${ }^{13}$, ao provocar deleções multi- 


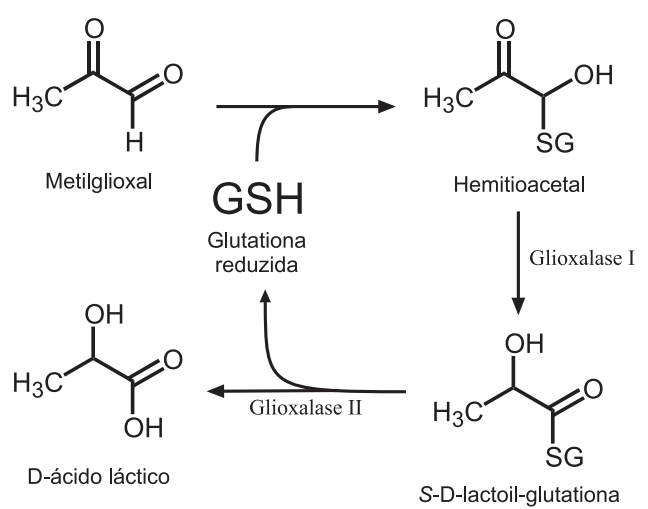

Esquema 6. Sistema das glioxalases

bases $(50 \%)$ e substituição nos pares de base (35\%) em células de símios $^{96}$. As substituições (transversões) observadas in vivo mais importantes foram $\mathrm{G}: \mathrm{C} \rightarrow \mathrm{C}: \mathrm{G}$ e $\mathrm{G}: \mathrm{C} \rightarrow \mathrm{T}: \mathrm{A}^{96}$. Doses de aproximadamente $360 \mu \mathrm{mM}$ de MG são capazes de inibir o crescimento de células de leucemia humana 60 (HL60), enquanto doses de $520 \mu \mathrm{M}$ tornam inviáveis culturas destas células ${ }^{97}$. Outra observação importante é que MG inibe o fluxo de elétrons através do complexo I da cadeia respiratória mitocondrial e inativa a enzima gliceraldeído3-fosfato desidrogenase de células de carcinoma 'Ehrlich ascites' e de leucócitos de pacientes de leucemia, enquanto não exerce nenhum efeito nas mesmas células normais ${ }^{98,99}$.

Já apontamos nesta revisão que MG, na qualidade de um $\alpha$ oxoaldeído, deve estar envolvido em reações com proteínas chamadas de reações de Maillard ${ }^{14}$ através da formação inicial de bases de Schiff. In vitro sabe-se que MG é capaz de reagir com proteínas e formar produtos de Maillard fluorescentes. Estas reações entre MG e proteínas são inicialmente reversíveis e, geralmente, ocorrem com resíduos de arginina e lisina (formando derivados de glicosilaminas) e também com resíduos de cisteína (formando derivados de hemitioacetais $)^{100}$. Este equilíbrio inicial pode ser deslocado para a formação de produtos (inclusive pentosidinas), sendo os resíduos de arginina os mais susceptíveis a este tipo de modificação ${ }^{100}$. Estas proteínas modificadas por MG ligam-se a receptores na superfície celular de monócitos e macrófagos sofrendo, então, endocitose mediada por receptor e, subseqüientemente, degradação lisossomal ${ }^{101,102}$. Apesar de a glicose ser o açúcar fisiológico mais abundante, sua concentração efetiva na forma de cadeia aberta é de apenas $100 \mathrm{nM}$ no sangue para indivíduos normais e de $200-500$ nM em diabéticos. Já o MG está presente em concentrações estimadas em $5 \mu \mathrm{M}$ em indivíduos normais e aumentada de 2 a 6 vezes em diabéticos, sugerindo que MG possa ser tão eficiente quanto a glicose in vivo na modificação de proteínas ${ }^{84,103-106}$. Nos últimos anos, são inúmeros os trabalhos que descrevem adutos de MG com resíduos de $\operatorname{arginina}^{102,107}$, lisina ${ }^{108-110}$ e cisteína em proteínas in vivo e in vitro, resultando na formação de AGEs. Metilglioxal reage reversivelmente com resíduos de arginina e cisteína de proteínas em condições fisiológicas e, em etapas irreversíveis posteriores, formam os seguintes adutos (Esquema 7): $\mathrm{N}_{\delta}$-(4,5-diidroxi-4-metil-imidazolidin-2-il) ornitina (1), $\mathrm{N}_{\delta}$-(5-hidro-5-metil-imidazol-4on-2-il) ornitina (2) e $\mathrm{N}_{\delta}$-(5-metilimidazol-4-on-2-il) ornitina (3) ${ }^{104,108}$. No caso da reação entre MG e resíduos de lisina observa-se a formação de resíduos de $\mathrm{N}_{\delta}-(1$ carboxietil)lisina (4) e derivados do "crosslink" de resíduos de lisina e produtos intermediários. Tais adutos são similares àqueles derivados do processo de glicação de proteínas, exceto pelo fato de $\alpha$ oxoaldeídos modificarem preferencialmente resíduos de arginina, exatamente o contrário do observado no processo de proteínas modificadas pela glicose, cujo alvo são os resíduos de lisina ${ }^{104}$.

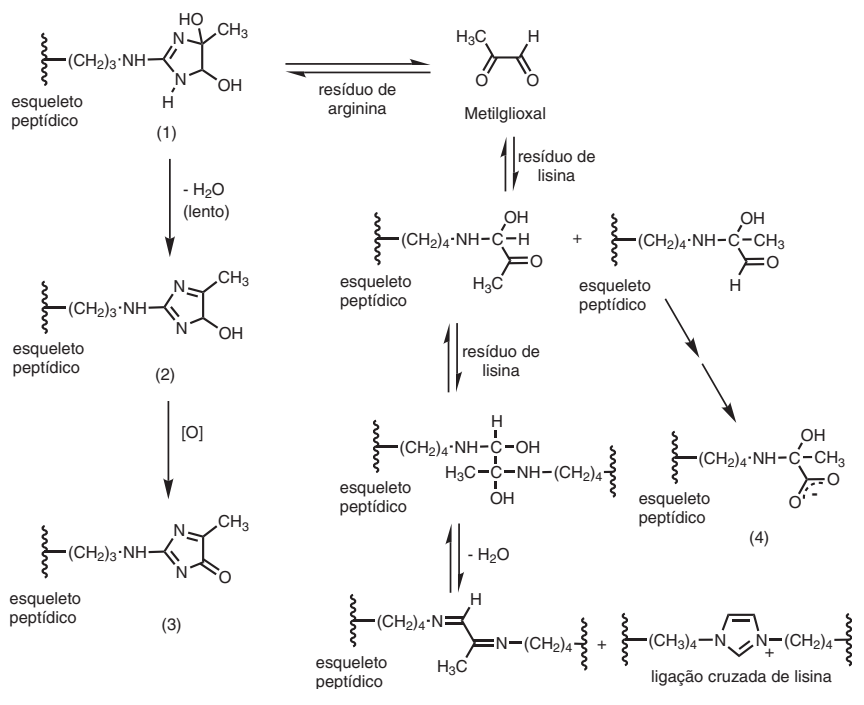

Esquema 7. Reação entre metilglioxal e resíduos de arginina ou lisina

Foi constatado que, além de ser um inibidor da SSAO, aminoguanidina pode prevenir a modificação irreversível de proteínas de plasma humano por $\mathrm{MG}^{111}$. Em virtude de diminuir a progressão de retinopatia, neuropatia e nefropatia em ratos com diabetes induzido ${ }^{112-115}$, prevenir a formação de ligações cruzadas em proteínas ${ }^{116}$ e prevenir a formação de fatores de reconhecimento para os receptores de AGEs com concomitante disfunção em células endoteliais, aminoguanidina tem sido considerada um possível agente terapêutico de pacientes com diabetes mellitus.

\section{AMINOACETONA E CRI-DU-CHAT}

A síndrome do cri-du-chat (choro de gato), descrita em 1963 por Lejeune e colaboradores ${ }^{117}$, é uma desordem genética, caracterizada pela deleção parcial, na parte distal ou intersticial, do braço curto do cromossomo 5 (5p-). Esta síndrome recebeu este nome porque sua principal característica, utilizada como diagnóstico em recém-nacidos, é o choro monotônico semelhante ao miado de um gato. Outras características desta síndome são microcefalia, deformações crânio-faciais e retardamento mental ${ }^{118.119}$. Talvez por ser uma síndrome rara (prevalência de 1:50.000 nascimentos), pouco tem sido relatado na literatura sobre as características bioquímicas ou fisiológicas desta síndrome ${ }^{120}$.

Kuhner e colaboradores ${ }^{6}$, estudando o metabolismo de aminoácidos nesta síndrome, descreveram um aumento na excreção diária de prolina e treonina em pacientes com cri-du-chat. Mais recentemente, Lejeaune e colaboradores ${ }^{121}$ observaram um significante aumento nas concentrações de asparagina e aspartato (Asx) em plasma e urina de pacientes com $\mathrm{cri}$-du-chat, enquanto histidina estava aumentada apenas na urina. Os autores atribuem o aumento de Asx a uma possível desordem no metabolismo de purinas, enquanto o aumento de histidina poderia estar ligado a outras deficiências no metabolismo geral de aminoácidos.

Caso seja confirmado o aumento de treonina circulante em portadores de $c r i-d u$-chat, é de se esperar que haja um concomitante aumento na concentração de AA e estabelecimento de estresse oxidativo nesta síndrome.

\section{OXIDAÇÃO NÃO-ENZIMÁTICA DE AMINOACETONA:} POSSÍVEL FONTE DE EROS EM DIABETES MELLITUS

Continuando os estudos do mecanismo de oxidação aeróbica 
de $\alpha$-aminocetonas acumuladas em desordens do metabolismo de aminoácidos, Bechara e colaboradores ${ }^{4}$ demonstraram que AA re- $^{-}$ age com oxigênio molecular, por um mecanismo semelhante ao proposto para ALA. Aminoacetona, porém, mostrou-se mais reativa, mesmo na ausência de catalisadores metálicos (ferro e cobre) ${ }^{4}$. A reação entre $\mathrm{O}_{2}$ e ALA na ausência de tais catalisadores é extremamente lenta. Verificou-se que na presença de íons ferro, AA sofre oxidação aeróbica por um mecanismo diferente do observado na ausência de metais. Este mecanismo provavelmente envolve a transferência simultânea de 2 elétrons (um proveniente de AA, outro de $\mathrm{Fe}(\mathrm{II})$ ) para oxigênio com formação direta de $\mathrm{H}_{2} \mathrm{O}_{2}, \mathrm{AA}^{\bullet}$ e $\mathrm{Fe}(\mathrm{III})$ (Esquema 8), tal como demonstrado anteriormente por Wallace e colaboradores ${ }^{122}$ ao estudarem a cinética de oxidação de hemoglobina a meta-hemoglobina na presença de vários nucleófilos. Outro mecanismo foi proposto por Kawanishi e colaboradores ${ }^{123}$ para a oxidação de AA catalisada por $\mathrm{Cu}$ (II), em que demonstraram um possível papel pró-oxidante de AA em lesões oxidativas a DNA. Neste trabalho os autores observaram um aumento nas concentrações de 8-oxo-diidro-2'-deoxyguanosina (8-oxodG) quando DNA de timo de bezerro foi incubado na presença de AA e $\mathrm{Cu}$ (II). Segundo os autores, esta reação é iniciada pela complexação de AA por $\mathrm{Cu}(\mathrm{II})$, seguida de dimerização oxidativa de AA formando 2,5-dimetilpirazina, MG e EROs como produtos.

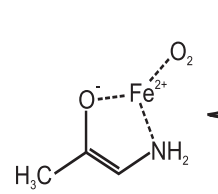

Aminoacetona (AA)

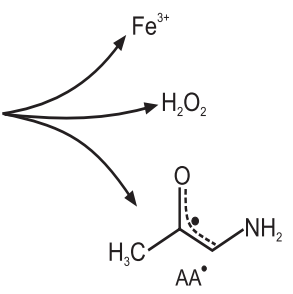

$\mathrm{AA}^{\circ}+\mathrm{O}_{2} \longrightarrow \mathrm{AA}_{\text {imino }}+\mathrm{O}_{2}$

$\mathrm{Fe}^{3+}+\mathrm{O}_{2}^{-*} \longrightarrow \mathrm{Fe}^{2+}+\mathrm{O}_{2}$

$\mathrm{Fe}^{2+}+\mathrm{H}_{2} \mathrm{O}_{2} \longrightarrow \mathrm{Fe}^{3+}+\mathrm{HO}^{-}+\mathrm{HO}^{\circ}$

$\mathrm{AA}+\mathrm{O}_{2}^{--} \longrightarrow \mathrm{AA}^{*}+\mathrm{H}_{2} \mathrm{O}_{2}$

$\mathrm{AA}+\mathrm{HO}^{\circ} \longrightarrow \mathrm{AA}^{\circ}+\mathrm{H}_{2} \mathrm{O}$

$\mathrm{AA}_{\text {imino }}+\mathrm{H}_{3} \mathrm{O}^{+} \longrightarrow \mathrm{MG}+\mathrm{NH}_{4}^{+}$
Esquema 8. Mecanismo de oxidação aeróbica de AA catalisada por $\mathrm{Fe}^{2+}$

Verificamos recentemente que a velocidade de consumo de oxigênio por AA é aumentada na presença de ferritina de baço de cavalo com a conseqüente liberação de ferro desta proteína ${ }^{5}$. A ferritina é uma proteína diretamente relacionada com o armazenamento de ferro em animais. Através de sua atividade ferroxidásica, é capaz de oxidar íons $\mathrm{Fe}(\mathrm{II})$ à sua forma $\mathrm{Fe}(\mathrm{III})$, menos efetiva para catálise de reações radicalares, exercendo então importante papel na desintoxicação deste metal ${ }^{124}$. Em paralelo, as EROs formadas durante a oxidação aeróbica de AA foram capazes de promover in vitro em ferritina e apoferritina: (i) modificação no seu comportamento eletroforético; (ii) oxidação de resíduos de triptofano e cisteína; (iii) perda da atividade ferroxidásica e (iv) perda da capacidade de incorporação de ferro (Esquema 9). Estes efeitos sobre ferritina adquirem alta relevância médica, pois o ferro é apontado como disparador de estresse oxidativo e danos a tecidos tanto em diabéticos humanos quanto em diabetes experimental ${ }^{125-127}$. Aminoacetona mostrou-se efetiva também em provocar agregação protéica em ceruloplasmina, proteína cuja verdadeira função metabólica ainda não se acha completamente esclarecida, mas que recentemente está sendo implicada na homeostase de ferro. Após a agregação protéica, CP perde tanto sua atividade ferroxidásica quanto aminoxidásica, atividades estas que são alvos atuais de nossos estudos direcionados à compreensão de seu papel metabólico. Segundo Akaike ${ }^{128}$, CP catalisa a oxidação unieletrônica do óxido nítrico (NO), produzindo intermedários capazes de sofrer adição nitrosativa a grupos tiólicos de proteínas. Estas proteínas nitrosadas possuem importante papel em transdução de sinais, transcrição gênica, apoptose e estresse oxidativo.

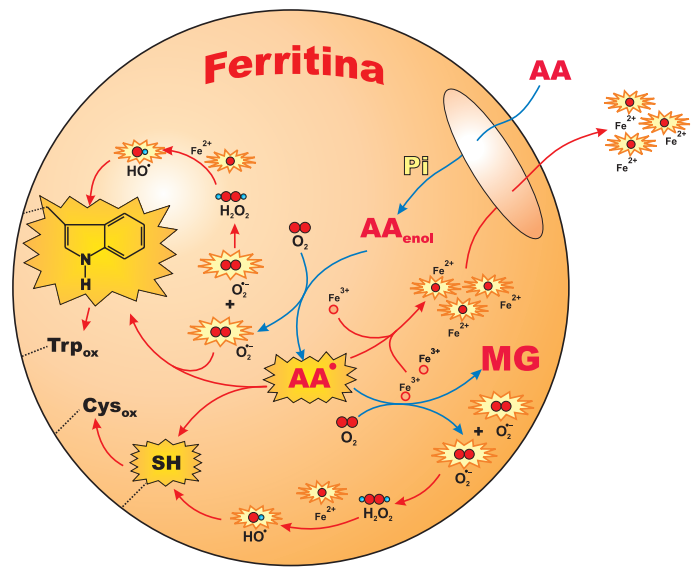

Esquema 9. Efeitos de aminoacetona sobre a ferritina: liberação de $\mathrm{Fe}^{2+} \mathrm{e}$ oxidação de resíduos de Trp e Cys de suas subunidades, com perda de capacidade estocadora de ferro e atividade ferroxidásica

\section{METABOLISMO DE HEXOSAMINAS}

Há farta documentação bibliográfica de que o acúmulo crônico de glicose plasmática durante o diabetes mellitus pode levar tanto ao descontrole da secreção da insulina (diabetes tipo I) quanto à resistência insulínica (diabetes tipo II) ${ }^{129-132}$. Como seqüela da hiperglicemia crônica, diabéticos estão sujeitos a complicações microvasculares (responsáveis por cegueira, neuropatias e falha renal) e macrovasculares (risco aumentado de infarto do miocárdio e amputações $)^{133}$. A correlação entre danos vasculares e a hiperglicemia crônica em diabetes mellitus foi estabelecida após observação de que células endoteliais expostas à hiperglicemia tem um aumento no fluxo de substratos, tanto na glicólise quanto no ciclo de ácidos tricarboxílicos ${ }^{12}$ para revisão detalhada. Nesta condição de excesso de substratos, há um aumento excessivo nos processos oxidativos mitocondriais, aumento no potencial transmembrana e aumento na produção de $\mathrm{O}_{2}{ }^{*-}$ pela cadeia de transporte de elétrons ${ }^{134}$. Este aumento induz uma redução na atividade da enzima gliceraldeídofosfato desidrogenase, acumulando então os intermediários da glicólise frutose-6-fosfato (F6P) e gliceraldeído-3-fosfato. O acúmulo de F6P é responsável pela iniciação da rota metabólica das hexosaminas, que possui como enzima chave a glutamina-F6P amidotransferase, responsável pela transformação de F6P em glicosamina-6-fosfato, que por sua vez é convertida em uridina difosfato- $N$-acetil-glicosamina (GlcNAc) ${ }^{134,135}$.

Várias evidências apontam a rota das hexosaminas como um sistema sensor de nutrientes capaz de modular a sensitividade celular à insulina, uma vez que os níveis intracelulares de glicosamina e de GlcNAc estão associados à disponibilidade de glicose, aminoácidos, ácidos graxos e nucleotídeos ${ }^{136,137}$. Estudos de Hazel e colaboradores $^{138}$ sugerem que a produção elevada de hexosaminas em tecido adiposo de camundongos é suficiente, por si só, para promover resistência insulínica. Outros estudos demonstram que hexosaminas induzem a modificação pós-translacional de fatores de transcrição e de algumas proteínas citosólicas, o que poderia, em parte, explicar o mecanismo molecular da resistência insulínica ${ }^{12}$. Além disso, glicosamina é capaz de ativar a expressão do gene $o b$ em células musculares e em adipócitos, exacerbando a excreção de leptina para o plasma ${ }^{139}$. A leptina é uma das proteínas circulantes sintetizadas e excretadas em resposta ao aumento no estoque de energia no tecido adiposo, responsáveis pela sinalização de saciedade nutricional ${ }^{140}$.

Além de um possível papel na regulação metabólica, as hexosaminas possuem efeito inibitório em crecimento de tumores, atra- 
vés da indução de modificações em biossíntese de proteínas, RNA e DNA em células tumorais ${ }^{141,142}$. Segundo Hiraku e Kawanishi ${ }^{10}$, uma possível explicação para a ação antitumoral de hexosaminas é a indução de apoptose por EROs formadas durante sua oxidação aeróbica. Estes pesquisadores demonstraram que hexosaminas são passíveis de sofrer oxidação aeróbica catalisada por cobre e promover in vitro danos a DNA de timo de bezerro. Neste estudo foi demonstrado que manosamina, frutosamina e glicosamina produzem compostos $\alpha$-dicarbonílicos e EROs como produtos de oxidação, através de dois possíveis mecanismos (Esquema 10). A rota principal envolve a oxidação aeróbica da hexosamina mediada por $\mathrm{Cu}(\mathrm{II})$, com a formação de um radical centrado no carbono e $\mathrm{Cu}(\mathrm{I})$. Este radical reage novamente com oxigênio para formar $\mathrm{O}_{2}{ }^{-}$, cuja dismutação gera $\mathrm{H}_{2} \mathrm{O}_{2}$, levando à formação do produto $\alpha$-dicarbonílico e $\mathrm{NH}_{4}^{+}$. A segunda rota, menos importante e observável apenas em concentrações de hexosaminas superiores a $1 \mathrm{mM}$, envolve a condensação de duas moléculas de hexosamina formando um derivado de diidropirazina. Este composto, por sua vez, sofreria oxidação catalisada por $\mathrm{Cu}(\mathrm{II})$ com a geração de $\mathrm{O}_{2}^{*-}, \mathrm{H}_{2} \mathrm{O}_{2}$ e um derivado de frutosazina. Em ambas as rotas, $\mathrm{o}_{2} \mathrm{O}_{2}$ reage com o $\mathrm{Cu}$ (I) formando um complexo metálico denominado peróxido de cobre $(\mathrm{I})(\mathrm{Cu}(\mathrm{I}) \mathrm{OOH})$, com atividade hidroxilante semelhante à de $\mathrm{HO}$ gerado na reação de Fenton ${ }^{143}$. O complexo $\mathrm{Cu}(\mathrm{I}) \mathrm{OOH}$ pode ser formado nas adjacências do DNA, provocando importantes modificações estruturais e com o subseqüente disparo de processos apoptóticos.

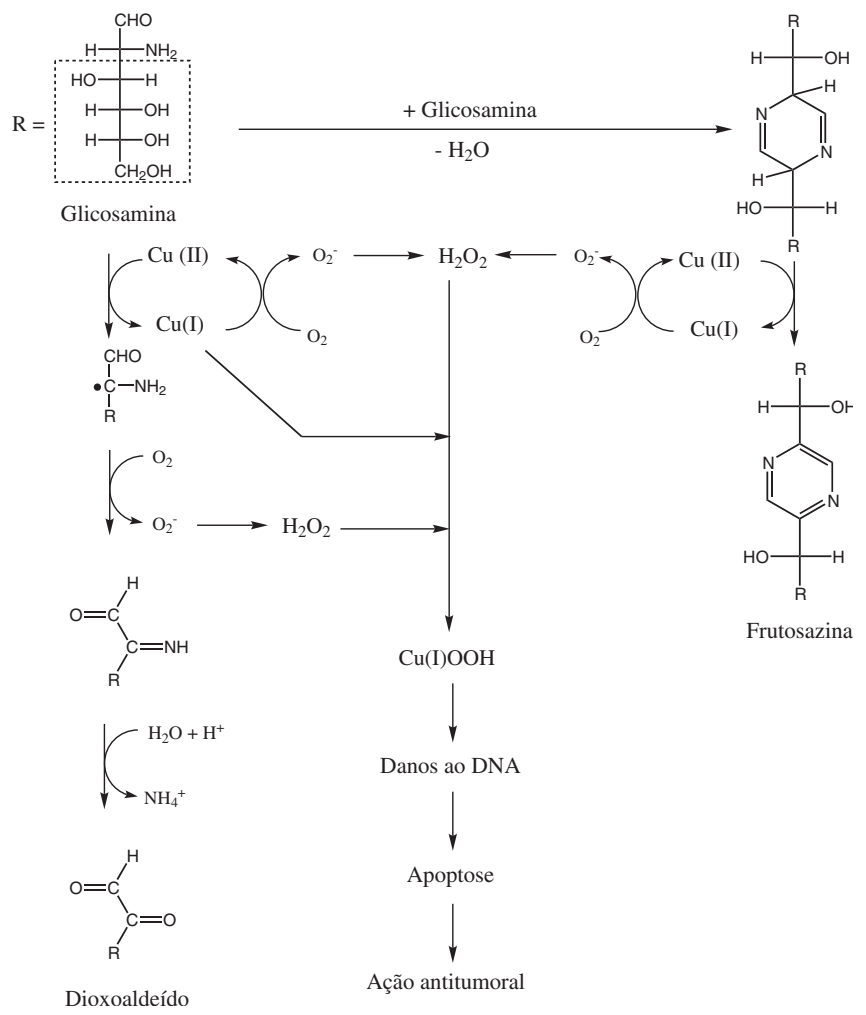

Esquema 10. Mecanismo de ação antitumoral de glicosamina

\section{CONCLUSÃO}

No presente artigo apresentamos alguns aspectos do metabolismo e da bioquímica de $\alpha$-aminocetonas endógenas e o seu envolvimento em algumas doenças genéticas e adquiridas. Nossa contribuição com a pesquisa do comportamento químico e biológico de ALA e AA demonstrara que estas duas $\alpha$-aminocetonas têm o potencial de agir in vivo como pró-oxidantes em porfirias, saturnismo, isoleucinemia e diabetes. O papel de ALA como fonte de EROs nas manifestações clínicas de PAI, plumbismo, terapia fotodinâmica à base de ALA e tirosinemia é hoje amplamente reconhecido pela literatura médica, por exemplo, nas revisões de Peng e colaboradores (terapia fotodinâmica) ${ }^{144}$, Meyer e colaboradores (manifestações neurológicas na PAI ${ }^{145}$, Cadet e colaboradores (danos a DNA catalisados por metais) ${ }^{146}$, Fuchs e colaboradores (terapia fotodinâmica ${ }^{56}$, Ryter e Tyrrel (metabolismo do grupo heme como fonte de pró-oxidantes) ${ }^{147}$ e Gurer e Ercal (antioxidantes no tratamento de contaminação por chumbo ${ }^{148}$.

Apesar de AA ser um pró-oxidante mais efetivo quando comparado com ALA, pouco se sabe sobre sua atuação como fonte de EROs in vivo. Sabe-se que AA é estável em soluções fortemente ácidas ( $\mathrm{HCl} 6 \mathrm{~N})$, mesmo quando aquecidas, e que esta estabilidade diminui em meio alcalino. Provavelmente devido à sua instabilidade frente a oxigênio e à rapida formação de bases de Schiff por MG, ainda não foram determinadas as concentrações fisiológicas e patológicas de AA em plasma e tecidos. Neste ponto é importante ressaltar que a determinação do mecanismo de oxidação aeróbica de AA na ausência de SSAO pode representar uma importante contribuição para o esclarecimento do papel do estresse oxidativo e do déficit na função respiratória mitocondrial observada em pacientes diabéticos.

\section{AGRADECIMENTOS}

Os autores agradecem o apoio do Conselho Nacional de Desenvolvimento Científico e Tecnológico (CNPq), da Fundação de Amparo à Pesquisa do Estado de São Paulo (FAPESP) e do Programa de Apoio a Núcleos de Excelência (PRONEX).

\section{REFERÊNCIAS}

1. Halliwell, B.; Gutteridge, J. M. C.; Free Radicals in Biology and Medicine, $3^{\text {rd }}$ ed. Oxford Science Publications, Oxford, 1999.

2. Bechara, E. J. H.; Medeiros, M. H. G.; Monteiro, H. P.; Hermes-Lima, M.; Pereira, B.; Demasi, M.; Costa, C. A.; Abdalla, D. S. P.; Onuki, J.; Wendel, C. M. A.; Mascio, P.; Quim. Nova 1993, 16, 385.

3. Douki, T.; Onuki, J.; Medeiros, M. H.; Bechara, E. J. H.; Cadet, J.; Di Mascio, P.; Chem. Res. Toxicol. 1998, 11, 150.

4. Dutra, F.; Knudsen, F. S.; Curi, D.; Bechara, E. J. H.; Chem. Res. Toxicol. 2001, 14, 1323.

5. Dutra, F.; Araki, D.; Bechara, E. J. H.; Free Radical Res. 2003, 37, 1113.

6. Kuhner, U.; Busse, M.; Buchinger, G.; Z. Kinderheilkd. 1974, 117, 259.

7. Reddi, O. S.; J. Pediatr. 1978, 93, 814.

8. Kalapos, M. P.; Biochim. Biophys. Acta 1999, 1426, 1.

9. Gibson, K. D.; Laver, W. G.; Neuberger, A.; Biochem. J. 1958, 70, 71.

10. Hiraku, Y.; Kawanishi, S.; Free Radical Res. 1999, 31, 389.

11. Laferrère, B.; García-Lorda, P.; Russell, C. D.; Pi-Sunyer, F. X.; Nutrition 2004, 20, 321.

12. Brownlee, M.; Nature 2001, 414, 813.

13. Szent-Györgyi, A.; Science 1941, 93, 609; Nature 1941, 148, 157; Science 1968, 161, 988; Bioenergetics 1973, 4, 533.

14. Monnier, V. M. Em The Maillard Reaction in aging, diabetes and nutrition; Baynes, J. W.; Monnier, V. M., eds.; Alan R. Liss Inc.: New York, 1989, p. $1-22$.

15. Vlassara, H.; Brownlee, M.; Monogue, K. R.; Dinarello, C. A.; Pasagian, A.; Science 1988, 240, 1546.

16. Kirstein, M.; Brett, J.; Radoff, S.; Ogawa, S.; Stern, D.; Vlassara, H.; Proc. Natl. Acad. Sci. U.S.A. 1990, 87, 9010.

17. Yan, S. D.; Schmidt, A. M.; Anderson, G. M.; Zhang, J.; Brett, J.; Zou, Y. S.; Pinsky, D.; Stern, D.; J. Biol. Chem. 1994, 269, 9889.

18. Vlassara, H.; Fuh, H.; Donnelly, T.; Cybulsky, M.; Mol. Med. 1992, 1, 447.

19. Schmidt, A. M.; Hori, O.; Chen, J. X.; Li, J. F.; Zhang, J.; Yan, S. D.; Brett, J.; Stern, D.; J. Clin. Invest. 1995, 96, 1395.

20. Hindmarsh, J. T.; Clin. Chem. 1986, 32, 1255. 
21. Kappas, A.; Sassa, S.; Galbraith, R. A.; Nordmann, Y. Em The metabolic basis of inherited disease; Scriver, C., ed.; McGraw-Hill: New York, 1989, p. $1305-1365$.

22. Stohs, S. J.; Bagchi, D.; Free Radical Biol. Med. 1995, 18, 321.

23. Gorchein, A.; Biochem. J. 1984, 219, 883.

24. Stein, J. A.; Tschudy, D. P.; Medicine 1970, 49, 1.

25. Gibson, J. B.; Goldberg, A.; J. Pathol. Bacteriol. 1956, 71, 495

26. Cavanagh, J. B.; Mellick, R. S.; J. Neurol. Neurosur. Ps. 1965, $28,320$.

27. Becker, D. M.; Kramer, S.; Medicine 1977, 56, 411.

28. Anzil, A. P.; Dozic, S.; Acta Neuropathol. 1978, 42, 121.

29. Lithner, F.; Wetterberg, L.; Acta Med. Scand. 1984, 215, 271.

30. Gubler, J. G.; Bargetzi, M. J.; Meyer, U. A.; Am. J. Med. 1990, 89, 540.

31. Thunnissen, P. L. M.; Meyer, J.; Dekoning, R. W.; Neth. J. Med. 1991, 38, 171.

32. Bechara, E. J. H.; Braz. J. Med. Biol. Res. 1996, $29,841$.

33. Mashino, T.; Fridovich, I.; Arch. Biochem. Biophys. 1987, 254, 547.

34. Thornalley, P. J.; Environ. Health Perspect. 1985, 64, 297.

35. Martin, J. P. Jr.; Batkoff, B.; Free Radical Biol. Med. 1987, 3, 241.

36. Chevion, M.; Navok, T.; Glaser, G.; Mager, J.; Eur. J. Biochem. 1982, 127, 405 .

37. Cadet, J.; Carvalho, V. M.; Onuki, J.; Douki, T.; Medeiros, M. H.; Di Mascio, P.; IARC Sci. Publ. 1999, 150, 103.

38. Costa, C. A.; Trivelato, G. C.; Pinto, A. M. P.; Bechara, E. J. H.; Clin. Chem. 1997, 43, 1196

39. Costa, C. A.; Trivelato, G. C.; Demasi, M.; Bechara, E. J. H.; J. Chromatogr., B: Biomed. Sci. Appl. 1997, 695, 245.

40. Penatti, C. A. A.; Bechara, E. J. H.; Demasi, M.; Arch. Biochem. Biophys. 1996, 335, 53

41. Fraga, C. G.; Onuki, J.; Lucesoli, F.; Bechara, E. J. H.; Di Mascio, P.; Carcinogenesis 1994, 15, 2241.

42. Timmins, G. S.; Liu, K. J.; Bechara, E. J. H.; Kotake, Y.; Swartz, H. M.; Free Radical Biol. Med. 1999, 27, 329.

43. Onuki, J.; Medeiros, M. H. G.; Bechara, E. J. H.; Di Mascio, P.; Biochim. Biophys. Acta 1994, 1225, 259.

44. Carvalho, H.; Bechara, E. J. H.; Meneghini, R.; Demasi, M.; Biochem. J. 1997, 328, 827.

45. Hermes-Lima, M.; Castilho, R. F.; Valle, V. G. R.; Bechara, E. J. H.; Vercesi, A. E.; Biochim. Biophys. Acta 1992, 1180, 201.

46. Oteiza, P.; Bechara, E. J. H.; Arch. Biochem. Biophys. 1993, 305, 282.

47. Demasi, M.; Costa, C. A.; Pascual, C.; Llesuy, S.; Bechara, E. J. H.; Free Radical Res. 1997, 26, 235.

48. Rocha, M. E. M.; Bandy, B.; Costa, C. A.; Barros, M. P.; Pinto, A. M. P.; Bechara, E. J. H.; Free Radical Res. 2000, 32, 343.

49. Rocha, M. E. M.; Ferreira, A. M. D. C.; Bechara, E. J. H.; Free Radical Biol. Med. 2000, 29, 1272

50. Rocha, M. E. M.; Dutra, F.; Bandy, B.; Baldini, R. L.; Gomes, S. L.; Faljoni-Alario, A.; Líria, C. W.; Miranda, M. T. M.; Bechara, E. J. H.; Arch. Biochem. Biophys. 2003, 409, 349.

51. Weishaupt, K. R.; Gomer, C. J.; Dougherty, T. J.; Cancer Res. 1976, 36, 2326.

52. Oseroff, A. Em Clinical Photomedicine; Lim, H.; Sorter, N., eds.; Marcel Dekker: New York, 1993, p. 387-402.

53. Lang, K.; Lehmann, P.; Bolsen, K.; Ruzicka, T.; Fritsch, C.; Expert. Opin. Investig. Drugs 2001, 10, 1139.

54. Wolfsen, H. C.; Ng, C. S.; Cutis 2002, 69, 140.

55. Duez, P.; Hanocq, M.; Dubois, J.; Carcinogenesis 2001, 22, 771.

56. Fuchs, J.; Weber, S.; Kaufmann, R.; Free Radical Biol. Med. 2000, $28,537$.

57. Onuki, J.; Teixeira, P.C.; Medeiros, M. H. G.; Di Mascio, P.; Quim. Nova 2002, 25, 594 .

58. Elliott, W. H.; Biochem. J. 1960, 74, 90.

59. Elliott, W. H.; Biochem. J. 1960, 74, 478

60. Bird, M. I.; Nunn, P. B.; Lord, L. A. J.; Biochim. Biophys. Acta 1984, 802, 229.

61. Bird, M. I.; Nunn, P. B.; Biochem. J. 1983, 214, 687.

62. Urata, G.; Granick, S.; J. Biol. Chem. 1963, 238, 811.

63. Boylan, S. A.; Dekker, E. E.; J. Biol. Chem. 1981, 256, 1809.

64. Tressel, T.; Thompson, R.; Zieske, L. R.; Menendez, M. I. T. S.; Davis, L.; J. Biol. Chem. 1986, 261, 16428.

65. Davis, A. J.; Austic, R. E.; J. Nutr. 1997, 127, 738.

66. Jagt, D. L. V.; Hassebrook, R. K.; Hunsaker, L. A.; Brown, W. M.; Royer, R. E.; Chem. Biol. Interact. 2001, 130-132, 549.

67. Ray, S.; Ray, M.; J. Biol. Chem. 1983, 258, 3461.

68. Ray, S.; Ray, M.; J. Biol. Chem. 1987, 262, 5974

69. Boor, P. J.; Trent, M. B.; Lyles, G. A.; Tao, M.; Ansari, G. A. S.; Toxicology 1992, 73, 251 .

70. Lyles, G. A.; J. Neural Transm. 1994, 41, 387.

71. Lewinsohn, R.; Braz. J. Med. Biol. Res. 1984, 17, 223.
72. O’Sullivan, J.; Unzeta, M.; Healy, J.; O’Sullivan, M. I.; Davey, G.; Tipton, K. F.; Neurotoxicology 2004, 25, 303.

73. Boomsma, F.; Van den Meiracker, A. H.; Winkel, S.; Aanstoot, H. J.; Batstra, M. R.; Veld, A. J. M.; Bruining, G. J.; Diabetologia 1999, 42, 233.

74. Boomsma, F.; Van Veldhuisen, D. J.; Kam, P. J.; in't Veld, A. J. M.; Mosterd, A.; Lie, K. I.; Schalekamp, M.A.D.H.; Cardiovasc. Res. 1997, 33, 387.

75. Yu, P. H.; Zuo, D. M.; Diabetologia 1997, 40, 1243.

76. Lyles, G. A.; Mcdougall, S. A.; J. Pharm. Pharmacol. 1989, 41, 97.

77. Lewinsohn, R.; J. Pharm. Pharmacol. 1981, 33, 569.

78. McLellan, A. C.; Phillips, S. A.; Thornalley, P. J.; Anal. Biochem. 1992, 206, 17

79. Dijk, J. V.; Boomsma, F.; Clin. Chim. Acta 1998, 270, 189.

80. Chalmers, J.; Lyles, G. A.; Biochem. Pharmacol. 1995, 49, 416.

81. Hysmith, R. M.; Boor, P. J.; Toxicology 1988, 51, 133.

82. Yu, P. H.; J. Neural Transm. 1998, 52, 201.

83. Yu, P. H.; Zuo, D.; Davis, B. A.; Biochem. Pharmacol. 1994, 47, 1055.

84. Kalapos, M. P.; Toxicol. Lett. 1999, 110, 145.

85. Baynes, J. W.; Diabetes 1991, 40, 405.

86. Thornalley, P. J.; Gen. Pharmac. 1996, 27, 565.

87. Kalapos, M. P.; Toxycol. Lett. 1994, 73, 3.

88. Kalapos, M. P.; Biochem. Educ. 1992, 20, 27.

89. Dakin, H. D.; Dudley, H.W.; J. Biol. Chem. 1913, 14, 155

90. Neuberg, C.; Biochem. Z. 1913, 49, 502.

91. Thornalley, P. J.; Biochem. J. 1990, 269, 1.

92. Atkins, T. W.; Thornalley, P. J.; Diabetes Res. 1989, 11, 125.

93. Kalapos, M. P.; Littauer, A.; de Groot, H.; Arch. Toxicol. 1993, 67, 369.

94. Haik, G. M.; Lo, T. W. C.; Thornalley, P. J.; Exp. Eye Res. 1994, 59, 497.

95. Shipanova, I. N.; Glomb, M. A.; Nagaraj, R. H.; Arch. Biochem. Biophys. 1997, 344, 29.

96. Murata-Kamiya, N.; Kamiya, H.; Kaji, H.; Kasai, H.; Mutat. Res. 2000 , $468,173$.

97. Ayoub, F. M.; Allen, R. E.; Thornalley, P. J.; Leuk. Res. 1993, 17, 397.

98. Biswas, S.; Ray, M.; Misra, S.; Dutta, D. P.; Ray, S.; Biochem. J. 1997, 323, 343.

99. Ray, S.; Dutta, S.; Halder, J.; Ray, M.; Biochem. J. 1994, 303, 69.

100. Westwood, M. E.; Thornalley, P. J.; J. Protein. Chem. 1995, 14, 359.

101. Westwood, M. E.; Thornalley, P. J.; Diabet. Med. 1995, 12 (suppl. 2-10), 549

102. Westwood, M. E.; Argirov, O. K.; Abordo, E. A.; Thornalley, P. J.; Biochim. Biophys. Acta 1997, 1356, 84.

103. Abordo, E. A.; Harjit, S. M.; Thornalley, P. J.; Biochem. Pharmacol. 1999, 58,641

104. Thornalley, P. J.; Chem. Biol. Interact. 1998, 111-112, 137.

105. Chaplen, F. W. R.; Fahl, W. E.; Cameron, D. C.; Proc. Natl. Acad. Sci. U.S.A. 1998, 95, 5533.

106. Shamsi, F. A.; Partal, A.; Sady, C.; Glomb, M. A.; Nagaraj, R. H.; J. Biol. Chem. 1998, 273, 6928.

107. Al-Abed, Y.; Mitsuhashi, T.; Ulrich, P.; Bucala, R.; Bioorg. Med. Chem. Lett. 1996, 6, 1577.

108. Odani, H.; Shinzato, T.; Usami, J.; Matsumoto, Y.; Frye, E. B.; Baynes, J. W.; Maeda, K.; FEBS Lett. 1998, 427, 381.

109. Lee, C.; Yim, M. B.; Chock, P. B.; Yim, H. S.; Kang, S. O.; J. Biol. Chem. 1998, 273, 25272

110. Ahmed, M. U.; Frye, E. B.; Degenhardt, T. P.; Thorpe, S. R.; Baynes, J. W.; Biochem. J. 1997, 324, 565.

111. Lo, T. W. C.; Selwood, T.; Thornalley, P. J.; Biochem. Pharmacol. 1994, 48,1865 .

112. Hammes, H. P.; Stradter, D.; Weiss, A.; Bretzel, R. G.; Federlin, K.; Brownle, M.; Diabetologia 1995, 38, 656

113. Cameron, N. E.; Cotter, M. A.; Dines, K.; Love, A.; Diabetologia 1992, 35,946 .

114. Sugimoto, K.; Yagihashi, S.; Microvasc. Res. 1997, 53, 105.

115. Soulis-Liparota, T.; Cooper, M.; Papazoglou, D.; Clarke, B.; Jerums, G.; Diabetes 1991, 40, 1328

116. Allen, R. E.; Lo, T. W.; Thornalley, P. J.; J. Protein Chem. 1993, 12, 111.

117. Lejeune, J.; Lafourcade, J.; Berger, R.; Vialatte, J.; Boeswillwald, M.; Seringe, P.; Turpin, R.; C.R. Acad. Sci. Paris 1963, 257, 3102.

118. Niebuhr, E.; Hum. Genet. 1978, 44, 227.

119. Wilkins, L. E.; Brown, J.; Wolf, B.; J. Pediatr. 1980, 97, 401

120. Mainard, P. C.; Clin. Genet. 2000, 57, 459.

121. Lejeune, J.; Rethore, M. O.; Peeters, M.; de Blois, M. C.; Rabier, D.; Parvy, P.; Bardet, J.; Kamoun, P.; Ann. Genet. 1990, 33, 16.

122. Wallace, W. J.; Houtchens, R. A.; Maxwell, J. C.; Caughey, W. S.; J. Biol. Chem. 1982, 257, 4966

123. Hirahu, Y.; Sugimoto, J.; Yamaguchiand, T.; Kawanishi, S.; Arch. Biochem. Biophys. 1999, 365, 62.

124. Theil, E. C.; Annu. Rev. Biochem. 1987, 56, 289. 
125. Niederau, C.; Z. Gastroenterol. 1999, suppl. 1, 22.

126. Nickander, K. K.; McPhee, B. R.; Low, P. A.; Tritschler, H.; Free Radical Biol. Med. 1996, 21, 631.

127. Young, I. S.; Tate, S.; Lightbody, J. H.; McMaster, D.; Trimble, E. R.; Free Radical Biol. Med. 1995, 18, 833.

128. Akaike, T.; Free Radical Res. 2000, 33, 461.

129. Anello, M.; Rabuazzo, A. M.; Degano, C.; Caltabiano, V.; Patané, G.; Vigneri, R.; Purrello, F.; Diabetes 1996, 45, 502.

130. Eizirik, D. L.; Korbutt, G. S.; Hellerstrom, C.; J. Clin. Invest. 1992, 90 1263.

131. Purrello, F.; Vetri, M.; Gatta, C.; Gullo, D.; Vigneri, R.; Diabetes 1989 $38,1417$.

132. Rossetti, L.; Giaccari; A.; De Fronzo, R. A.; Diabetes Care 1990, 13, 610.

133. Ceriello, A.; Diabetes Care 2003, 26, 1589.

134. Hammes, H. P.; J. Diabetes Complicat. 2003, 17, 16.

135. Cheatham, B.; Endocrinology 2004, 145, 2115.

136. Marshall, S.; Bacote, V.; Traxinger, R. R.; J. Biol. Chem. 1991, 266, 4706.

137. McClain, D. A.; J. Diabetes Complicat. 2002, 16, 72.

138. Hazel, M.; Cooksey, R. C.; Jones, D.; Parker, G.; Neidigh, J. L.; Witherbee, B.; Gulve, E. A.; McClain, D. A.; Endocrinology 2004, 145, 2118.
139. Wang, J.; Liu, R.; Hawkins, M.; Barzilai, N.; Rossetti, L.; Nature 1998, 393, 684.

140. Campfield, L. A.; Smith, F. J.; Guisez, Y.; Devos, R.; Burn, P.; Science 1995, $269,546$.

141. Bekesi, J. H.; Bekesi, E.; Winzler, R. J.; J. Biol.Chem. 1969, 244, 3766.

142. Raisys, V. A.; Winzler, R. J.; P. Soc. Exp. Biol. Med. 1971, 138, 893.

143. Oikawa, A.; Kawanishi, S.; Biochim. Biophys. Acta 1998, 1399, 19.

144. Peng, Q.; Berg, K.; Moan, J.; Kongshaug, M.; Nesland, J. M.; Photochem. Photobiol. 1997, 65, 235.

145. Meyer, U. A.; Schuurmans, M. M.; Lindberg, R. L. P.; Semin. Liver Dis. 1998, 18,43

146. Cadet, J.; Douki, T.; Pouget, J.-P.; Ravanat, J. L.; Sauvaigo, S.; Teixeira, P. C.; Onuki, J.; Medeiros, M. H. G.; Bechara, E. J. H.; Di Mascio, P. Em New Aspects of Trace Elements Research; Abdulla, M.; Bost, M.; Gamon, S.; Arnaud, P.; Chazot, G., eds.; Smith-Gordon: London, 1999, cap. 39.

147. Ryter, S. W.; Tyrrel, R. M.; Free Radical Biol Med. 2000, 28, 289.

148. Gurer, H.; Ercal, N.; Free Radical Biol. Med. 2000, 29, 927. 